\title{
Approaches to Teaching Literary Translation
}

\author{
ZHANG Yan \\ Shanghai Institute of Technology, Shanghai, China
}

\begin{abstract}
As one of the methods of teaching foreign language, translation is a necessity in foreign language classroom. When doing translation, students should be able to understand the materials well and be equipped with basic translation theories in order to promote their translation ability. Literary translation is more complex and more creative, compared to the translation of other writing forms. In addition to understanding the cultural background of source text, personality of author, and other subjects that are associated with the original, learning some basic literary translation theories is helpful to the translation.
\end{abstract}

Keywords: approach, literary translation, teaching

\section{Introduction}

Translation, as a tool of teaching foreign language, offers a continued means of developing and practicing skills for foreign language students (Round, 1998). The act of translating is defined by Peter Newmark (1991) as: "transferring the meaning of a stretch or a unit of language, the whole or a part of a text, from one language to another" (p. 27). The use of translation develops the three qualities to all language learning: accuracy, clarity, and flexibility. It trains the learner to search (flexibility) for the most appropriate words (accuracy) to convey what is meant (clarity) (Duff, 1994). Many teachers abide by the rule of "learning translations through translation practice" in the whole process. But theoretical bases or scientific methods should be concerned as well. If teachers either check the answers in class one sentence after another, or use some model to prove certain translation skills, students cannot really systematically learn the literary translation methods.

Because of the feature of literature, the differences between literary translation and other functional writing's translation are obvious. Each literary has its own unique style which was created by the author. Literary translation is also a creative activity with strong artistic and personality features. The other functional writings, such as advertisements, documents, English for science and technology, have their certain types and structures. Changing styles of these materials is quite limited. In literary translation, the translator should not only translate the original meaning faithfully and expressively, but also convey the original style to the readers of translation. At the same time, literary translation has clear links with other disciplines, such as linguistics, language studies, comparative literature, and cultural studies. It is therefore proposed that the teachers should consider using appropriate approaches to the teaching literary translation.

\section{Approaches to the Teaching of Literary Translation}

\section{Instructive Function of Translation Theories}

Teachers should handle the relationship between translation theories and practice appropriately. 
Translation theories and practice are the same important aspects in learning and teaching translation. Teachers ought to teach translation skills as well as translation theories. Some teachers think that practice is the only way in translation learning, and then neglect that the authentic theories have instructive function to translation practice. Usually, it is planned that translation teaching should be conducted after language learning. Although students have already had the foundation of basic language abilities, they have never learnt the translation theories or skills systematically. The translation abilities they have are the accumulation of perceptive knowledge. Numerous translators or theorists, in ancient or at present, have left us so many priceless theories concerning various aspects of translation. If students learnt those theories, which were extracted from the former practice by others, and use them appropriately, their ability of translation would be improved rapidly. Translator equipped with theoretical knowledge is more flexible in method and clearer in purpose of translation than who knows nothing about theory.

Teacher should offer students a general comprehension of the history and development of translation theories, give them some ideas of the new achievement or trend in the theoretical research, such as Engine. A. Nidet's equivalence of response, Tytler's translation principles, Roman Jacobson's three divisions of translation, etc. Translation is such a complicated process that there are many debates in translation studies. But the goal of teaching translation in second language learning class is making students familiar with the basic theories about literary translation. Holding this aim of teaching, teachers could decide how to introduce theories in class. Under the instruction of literary translation theories, translation practice is necessary because it makes students understand theories well.

On the other hand, literature translation is a creative process. Students' practice should not be bounded or controlled by any theory. When commentating on student's translation, teacher should not take a reference translation as a standard translation. Reference translation is just a referential material. As a creative activity, the results of translation are reasonable to be different.

\section{Related Courses}

Teaching literary translation is as complex, divided, and sophisticated an activity as much literary translation itself. Furthermore, such teaching has a dual component since it comprises the study of two or more cultures as well as two languages. A full time literary translation program contains a number of disparate courses, such as translation of various styles, backgrounds in topics and cultures, author's personality, etc. Students should not only have the ability to write well in both mother language and foreign language, but also know the cultural background of source text, personality of author, and other subjects that are associated with the original.

In literary translation, the handling of literary style is the most difficult skill. In order to master the original style, students should read some background materials about the original. Teacher should give enough information about the original text to students before translation practice. As such, the practical translation classes and the specialist subject classes should be coordinated as far as possible to coincide so that students can gain maximum benefit from the preparation.

\section{Criticism}

Criticism in teaching process is different from ordinary literary criticism. As participants, students should translate source text themselves first. Teachers or classmates would criticize their translated text. On the other hand, they have chances to criticize the reference translation offered by teacher or classmates. In the process of 
the dual directional criticizing, students are not only the people being criticized, but also critics themselves. The enthusiasm for learning translation is enhanced; the practical ability is improved as well.

When commentating on translation, students should analyze from a few specific viewpoint, including a detailed analysis of specific points in the source text and comparison of the treatment of those points in the target text. The specific points should be analyzed include:

Title. Students are drawn to the significance of the title in a literary text, that is, its fulfilling not simply a linguistic referential function, but also a major function in conveying the message of the text. Students should have a discussion about how effectively the translated title performed the functions that have already been specified, and what degree of equivalence with the source text title.

Crucial words and phrases. They are words or phrases which the source text writer uses repeatedly for the purpose of highlighting a particular personality trait in the characters, or for plot development, or for revelation, or development of theme. The critical questions are the same as those raised in the discussion of the translated title.

Crucial junctions in the thematic development. By paying attention to the writer's use of the technique of contrast, the decisive moments of change can be identified and their significance in the thematic development of the works can be accessed.

Genre and writing style of the text. Different genres of texts have different writing conventions, and a writer's writing style can usually be described as typical of that convention, excelling within that convention, or conversely, as innovative or experimental.

Cultural difference. Due to differences between source and target culture, some translation problems cannot be avoided. Being practicing learners would really be alert to these problems. The more a learner is aware of culture difference, the better translation he will do. Cultural difference has been one of the focuses of translation theories. Teachers should lead students to the right understanding of the theories about it and suggest students practice more.

Overall treatment of the source text. Literary translation is a process of creation as well as a process of linguistic transference. The translated text should be regarded as a whole new piece of work, but it has to be done on the basis of the good understanding of the original text. The translation in general should be loyal to the original text, although the process would not always be smooth.

\section{Teaching Materials and Testing}

It is widely acknowledged that a good textbook should meet with the requirement of combining theories and practice of translation, be various in contents and form, be interesting and up-to-date. Textbook should probe into the major concerns of literary translation theories, and have lively text to be practical materials. The translation test can be divided into two parts. One part includes testing particular skills, some translation methods and theories. The other focuses on the translation practice to check translation abilities. Students should regularly have a clear indication of their progress. In any event, the grade is given to gladden or assure or alarm the students about their progress, not as a spur to competition, since one should be competing only against oneself or rather one's last performance, not against others.

\section{Conclusion}

With the growth of literary translation programs in China, it has been recognized that teaching of 
translation theories and other disciplines has positive effects on translation practice. Appropriate approaches to the teaching of literary translation should be employed in order to bring every positive factor into teaching practice, make full use of students' creative power, and promote their translation abilities.

\section{References}

Duff, A. (1994). Translation: Resource books for teachers. A. Maley (Ed.). Oxford: Oxford University Press.

LUO, X. Z. (1984). 翻译论集 (Essays on translation). 北京: 商务出版社.

Newmark, P. (1991). Approaches to translation. GB: Multilingual Press.

Nida, E. (1975). Language, culture and translation. Oxford: Oxford University Press.

Round, N. (1998). Monuments, Makars and modules. In P. Bush and Kirsten Malmkjær (Eds.), Rimbaud's rainbow: Literary translation in higher education. Amsterdam/Philadelphia: John Benjamins.

Savory, T. H. (1968). The art of translation. London: Cape.

ZHANG, J. (1987). 文学翻译原理 (Theories on literary translation). 河南: 河南大学出版社. 